Julian Nida-Rümelin

Eine Theorie praktischer Vernunft 



\section{Julian Nida-Rümelin}

Eine Theorie

praktischer Vernunft

DE GRUYTER 
ISBN 978-3-11-060353-8

e-ISBN (PDF) 978-3-11-060544-0

e-ISBN (EPUB) 978-3-11-060367-5

Library of Congress Control Number: 2019957137

\section{Bibliografische Information der Deutschen Nationalbibliothek}

Die Deutsche Nationalbibliothek verzeichnet diese Publikation in der Deutschen Nationalbibliografie; detaillierte bibliografische Daten sind im Internet über http://dnb.dnb.de abrufbar.

(c) 2020 Walter de Gruyter GmbH, Berlin/Boston Autorenporträt: (C) Diane von Schoen

Druck und Bindung: $\mathrm{CPI}$ books $\mathrm{GmbH}$, Leck

www.degruyter.com 
Der Künstler Ai Weiwei meinte (befragt nach seinem Umgang mit chinesischen Sicherheitskräften): „Man kann nicht sagen, dass die anderen gar keine Vernunft besitzen. Wenn es so wäre, bräuchte man schon nicht mehr miteinander zu sprechen. Menschen sprechen nicht mit Ziegelsteinen.“ zitiert nach Byung-Chul Han: „Sein Leben ist mehr als einfach nur Widerstand. Eine Verteidigung Ai Weiweis gegen seine Kritiker und Bewunderer“, in FAS vom 30. August 2015, S. 43

Rolf, Margret und Martine Nathalie, Juliette, Colette und Noel gewidmet 
